\title{
The emergence of electronic books publishing in Spain
}

\begin{abstract}
.
After reference books and scientific journals, electronic books represent the next level of evolution in the digital revolution. Their presence in libraries and their level of knowledge on the part of users is still low. But the development of specific collections by the publishers, the development of increasingly refined online distribution systems and the improvements in portable reading devices (e-book readers) are causing a change in this situation, along with a turnaround on the production and consumption of such documents. In Spain, recent experiences by publishing houses are related to this new market, and they will change the current publishing scene in no time. This article discusses some of them and gives an outlook of future developments in the sector.
\end{abstract}

Keywords

e-books, electronic publishing, e-readers, market publishing, Spanish publishing, e-book devices.

\section{Classifications: Case Study}

\section{Electronic Publishing}

Electronic publishing is a strong reality in all the countries in the Western world. According to Lee (2002), 93\% of all the newly produced information is being created on a digital format. Scientific journals marked the beginning of this trend, and they are now established as indisputable digital models in the academic field. For their part, scientific monographs and mainstream publications, after several years subject to contradictory movements, moving forwards and backwards in line with the successes and failures of technology, seem to have started a tendency that is becoming more and more consolidated, and all data seem to confirm it. The growth rate in the production and demand of electronic books has grown by approximately 20\% in the last few years (Just, 2007; Alvite Diez, Rodriguez Bravo, 2009). Outsell (2009) increases this estimate up to a progression of $50 \%$ in the last years. In December 2008 alone, the sales of electronic books in the US had risen by $118 \%$. Likewise, in the last two years, one million e-book readers have been sold. According to the APA, "Ebooks saw a 23.6 percent increase from last year with $\$ 67$ million in sales and a compound growth rate of 55.7 percent since 2002" (APA, 2009). The sales statistics offered by the International Digital Publishing Forum (IDPF, 2009) confirm this trend of increasing sales with a very significant growth in the last years.

This situation comes as the result of the transformations the publishing sector has gone through in the last few years.

TThe most significant change has been the digital management of contents. After the digital revolution, it has been made clear that the core of the publishing business over the next years will be focused on the acquisition and development of those contents. The publishers' task, its very immutable core, regardless of the technological context around them, their raison d'être is working with the contents and creating an added value through a proper production, 
legibility and readability, thus guaranteeing that their reception will be as efficient as possible. This is an especially relevant matter, now that the latest developments in the field of electronic edition, related to the portable reading devices (the e-book readers), are a reality that is opening market opportunities for the publishers that were unthinkable before. E-book readers are beginning to become popular, and their use in recreational reading is more and more frequent (Nelson, M., 2008; Anderson, B. 2009), even though nobody thought they could compete in that field with traditional books (Berube, L., 2005). Electronic reading of texts about academic research, on the other hand, is considered to be one of its future potentials, as was shown in one of the pilot projects of Amazon with universities (in Princeton, to be precise ${ }^{1}$ ). Textbooks were replaced with digital editions that students had to read with the big-screen Kindle DX device. The results of this experience pointed towards some critical factors, such as the slowness of the device and, most importantly, the lack of functions capable of replacing the traditional interaction between the students and the paper: underlining text, adding notes or post-its, etc. These deficiencies in the device and the technology will be solved thanks to the developments and innovations that are constantly being added. Once the jump towards recreational reading has been made, the next step will be research and academic reading.

Electronic books represent the third wave in the development of electronic publishing.

An electronic book is any type of file in a digital format that can be downloaded as such into an electronic device for its visualization. Ultimately, it is a digital file that requires an additional element in order to be viewed: the reading device, which must include the proper software for the reading of the document. Generally speaking, an electronic book is quite similar to its printed version, only its medium changes. In a conventional book, the only medium is paper, whereas an electronic book can be presented in a computer, a reading device, a PDA, a mobile phone or a tablet PC. Its contents are usually available in PDF, HTML, XML, ePub, mobipocket or other formats, such as plain text. Its features allow for great versatility and mobility.

fter the emergence of reference works that could be looked up from a remote server or via a CD-ROM and electronic journals, which are document types fully established as customary bibliographical references, now it is the turn of electronic books, which, according to Rao (2005), are the most important revolution in the world of literature after Gutenberg. This author states that the favourable forecasts for the implementation of e-books are based on a series of factors such as the quick development of information infrastructures, the growing volume of contents that are published digitally, the constant improvement of the characteristics of digital publications (multimedia systems, hypertext, interactivity, etc.), and the development of technologies that make it possible for electronic books to behave like their traditional counterparts. The most recent research and analysis bear witness to this trend, which consists of a progressive penetration of electronic monographs in the publishing

\footnotetext{
${ }^{1}$ The program was called: "Toward Print-Less and Paper-Less Courses: Pilot Amazon Kindle Program".
} 
market. These monographs are mainly directed towards the academic and scientific fields, in which new learning methods have appeared, such as the "electronic study packs" or the "learning packs" (Secker, J; Plewes, L. 2002; Mclellan, R.J.; Hawkins, N. 2006). Some studies carried out by Springer (2008), Publishers Communication Groups (2008), the Centre for Information Behaviour and the Evaluation of Research (CIBER) (2008), or the Joint Information Systems Committee (JISC, 2008) confirm this supposition. The surveyed users from different fields reveal a growing interest in electronic formats for the access to monographs, preferably for their use in studies and research, and they predict a steady and increasing use of this format in the next years.

A study carried out by the JISC e-book observatory project between June 2008 and June 2009 (Stelle, L., Woodward, H.; 2009), in which more than 40.000 students took part, showed some interesting results with regard to their use of electronic books. It revealed that e-books were mainly used as a reference tool, instead of being used for a continued reading, because $70 \%$ of the students just leafed through separate chapters; that the usage ratio was 13 minutes per session (approximately 8 pages); that they were used as a supplementary reference, in order to complete the information they learned from the printed works they used for an in-depth reading; and that electronic books were not considered to be a replacement for printed books, thus having virtually no impact on the market. Their use was considered to be a complement instead of an autonomous solution. These results come as no surprise because, as several studies have already shown (Dillon, A, Gabbard, R. 1998; Doctorow, C, 2004; (Bellaver, R.F.; Gillette. 2004; Landoni, M; Hanlon, G. 2006; Kang, Y. et al, 2009), on-screen reading is more tiring than paper reading, and the level of content assimilation is lower. Plus, the patterns of consultation of electronic works are strongly influenced by the routines that had been acquired with reference works and scientific journals.

Currently, the users of libraries and information centres are becoming more and more familiar with electronic resources, such as reference works, databases and electronic journals with full texts. These resources have been easily adapted to the digital format, and they have been rapidly accepted and assimilated by the users. A few years ago, there were very few readers that could give documented answers about the use and knowledge of e-books (IDPF, 2006). However, nowadays more and more people know and handle these new formats. On the other hand, until very recently, e-book reading devices were almost non-existent in the libraries, in view of the many deficiencies they presented. Currently, many of those deficiencies have been solved. Electronic books are emerging as the last frontier that publishers, libraries and information centres alike must cross in order to adapt their resources to the digital revolution. The model of a static, unalterable and physically reproducible book with growing marginal costs that depend on sales is teetering due, on the one hand, to the pressure of these new communication paradigms and, on the other hand, to the disappearance of some of the barriers that hampered their use. Therefore, these new models are spreading their area of influence towards strictly commercial fields, as is proven by the success of some e-readers, such as Ilead or, more recently, Amazon's Kindle, with thousands of titles available for the users to download. In December 2009, Amazon has sold, for the first time, more eBooks than printed books. This virtual bookstore claims that this phenomenon is due to the success of its Kindle 
reader, which has taken advantage of the delays in the marketing of other competing products, such as the Barnes reader. The catalogue of titles for Kindle includes more than 390,000 books. Amazon states that more Kindle readers have been sold in December than, for example, iPods. The association of a reading device with a content distribution system has proven to be a successful business model, as has been seen in this example, or in the case of Barnes \& Noble and its Nook, Sony and its different versions of Sony Reader and the Sony Store and, more recently, Apple. This corporation already created iTunes, which was associated with iPod, its music playing device; or the App Store, associated with the iPhone. On January 27, 2010, Apple has presented iPad, its version of a PC tablet, which features multimedia applications, internet browsing and reading of eBooks. The supply of contents for this device will be carried out via iBooks, and there are five important publishing houses that have already signed an agreement to provide their books: Penguin, Harper Collins, Simon \& Schuster, MacMillan and Hachette.

\section{Electronic publishing in Spain}

In the case of Spain, electronic publishing increased by $88.2 \%$ in 2007 , in comparison with the previous year, and this growth has kept its trend in 2008 (Panorámica, 2009). Within this field, the edition of Internet files went up by $68.9 \%$, and it was especially important in the sector of Social Sciences and Technology, which represented $60 \%$ of the total, as was confirmed by the report Comercio Interior del Libro (2008). In 2008, the rise in the sector of Literary Creation has been particularly important, with an increase of $58.3 \%$, compared with last year. In 2008, according to the data issued by the Spanish Ministry of Culture, 8.847 electronic books were published, compared with 220 e-books in 1994. This shows the progression of these products, which already represent $8 \%$ of all the published production.

In November 2009, the report La digitalización del libro en España (The Digitalization of Books in Spain) was presented (Dosdoce, 2009). It stated that the digitalization of books will be one of the most strategic decisions that publishers will have to make in the next years, and that it will represent a general transformation of the publishing business, its production and distribution strategies, its future marketing policies and the market itself. The publishers' response to a survey designed to assess the digitalization trends over the next years are very significant in this particular moment of time. $57 \%$ of those polled consider that both "technologies" (paper and electronic) will coexist. Only 15\% of the workers in this field opined that electronic books will replace their paper counterparts.

$48 \%$ of the professionals in the publishing sector think that the main source of income of Spanish publishing houses in the year 2020 will still be paper books. Another $28.6 \%$ considers that electronic books will become the main source of income. $69 \%$ of them estimate that the main priority of publishing companies when faced against the challenge of book digitalization is the definition of their business model. According to this ranking of priorities, $48 \%$ of those polled think that the second most important decision the publishing groups will have to make in the following months is to invest in training their staff in order to be up to date with the impact of new technologies on their business. The future negotiation of digital 
rights over the works that are part of their list of titles ranks second in the list of priorities of the professionals in the book sector. Only $21 \%$ of those polled consider that the design of their websites is an "important" or "very important" priority, whereas for international publishing houses, it is one of the most important decisions regarding marketing and online sales of any cultural entity. $44 \%$ of the professionals that took the survey opine that the main beneficiary of the digitalization of books is the reader, and that bookshops will be the worst affected. $33.6 \%$ of those polled think that investing in training their staff in order to be up to date with the impact of new technologies on their business ranks third on the list of priorities. Of all 277 publishing companies that were polled, $40 \%$ consider that the retail price of digital books should be $50 \%$ lower than their paper counterparts. $27 \%$ of the publishing groups think that the retail prices of electronic books should be $30 \%$ lower than printed editions, whereas $21 \%$ think that there should be at least a $15 \%$ discount in electronic books. $10.5 \%$ of them consider that both versions (electronic and paper) should have the same price, and only $2.5 \%$ of them stated that digital versions should be more expensive than printed books. One of the measures that try to reduce prices and increase the marketing of electronic books in Spain was introduced in December 2009, and it reduced the VAT that charged these products from 16\% to $4 \%$, thus putting them on a level with conventional books.

The Federación de Gremios de editores, in collaboration with the Fundación Germán Sánchez Ruiperez published in February 2010 ((Federación Gremios Editores, 2010) a report on digital books, in which publishers are questioned about the following:

1. Existence of a digital project.

2. Impact of digitization in the catalog.

3. Formats and reading devices.

4. Sales and distribution channels.

\section{Pricing policy.}

Of the 254 publishers surveyed, $80 \%$ of these states that they made or planned actions in the digital area during the period 2009-2011. At the end of 2009, nearly half of publishers $(44 \%)$ had less than $5 \%$ computerized catalogs, but by 2011 they expect to have between $50 \%$ and $100 \%$ completely digitized. Small publishers are the ones that show a higher predisposition to the digitalization of their catalogs, so that at the end of 2011, a third of them (33\%) expect to have scanned between $50 \%$ and $100 \%$ of the catalogs, and by $2011,19 \%$ of these publishers will have the full catalog in digital version.

One of the fundamental aspects regarding the development of digitization programs has to do with marketing. In this connection about $20 \%$ of surveyed publishers will market between $50 \%$ and $100 \%$ of its innovations in digital version in addition to the printed version. This is extremely interesting because it signals abandonment of fear of cannibalization of print digital that characterized previously publishers. In fact, the editors show a clear inclination toward digital publication for the next two years. So major publishers (with over 10,000 books in the catalog), will provide an average of 405 and 538 titles exclusively conceived as digital works, during 2010 and 2011 respectively. 
Another issue of concern and controversy among editors, due to a variety of existing standards is the one of formats. PDF is the predominant format with $80 \%$ of publishers who will use it in 2010, but EPUB is the format that will grow faster, it will be used from $24 \%$ of publishers in 2009 to $60 \%$ in 2011. This is good news for consumers since the format is open and allows for greater exchange and transfer of information among them. One third of the editors prefer Mobipocket.

Very important are the expectations of publishers about the sales and distribution channels they intend to use. The largest publishers, but medium and small publishers too, think about this possibility, combined with the use of generic trading platforms and platforms shared with other publishers.

Pricing policies, one of the warhorses of the publishing industry in the digital context, and sensitive point in the development of a sustainable market niche, vary considerably from one publisher to another. Although largely provide lower prices than the printed work, since only $8 \%$ of publishers will keep the same price in both media, only $24 \%$ of publishers consider significant discounts (around 50\%) with respect to the printed work.

In any case, publishers are aware of the imminence and unavoidability of the process of migration or partial (or even total) substitution between the new model and the old one. In the last Frankfurt Book Fair, a survey with 1.000 experts of the publishing world from 30 different countries concluded that, by 2018, digital publishing will supersede traditional publishing. The survey came to other interesting conclusions: in China, digital publishing will multiply by 3 over the next few years, breaking the monopoly held by the United States; By 2018, Google search and Amazon, together with the consumers, will prefer digital books over the classic model; the sales of books online have been chosen as the most important milestone in the history of publishing in the last 60 years. One of the signs of this change is the fact that the Frankfurt Book Fair will soon cease to be called Book Fair, and it will be called Media Fair, due to the upsurge of digital media. In Spain, in 2009, the first digital book fair has been held, with the participation of digital publishing houses such as Publidisa, Leer-e, Grammata, Luarna Ediciones, 36L Books, Edicat, Liceus, Soopbook, Biblio 3000 and Bubok. All these participants used stands, round tables and workshops to share their experiences, their contents and all sorts of devices related to digital books and their value chain, as well as new artistic, educational and productive models favoured by the digital book. Other important organizations, institutions and specialized social networks that fulfil a prescriptive function, such as the Biblioteca Nacional, the Spanish Association of Digital Journals (ARDE), the Spanish Association of Community Managers (AERCO), Ediciona, Literaturas.com, Libro de notas, Revista de Libros, Dosdoce.com and Ilustrae, also shared a comprehensive overview of the current potential hidden under the label called "industry of written digital contents".

\section{The publication of electronic books in Spain}

\section{a. 1.1.1 Methodology}


In order to develop the current situation of electronic publishing and the research on the initiatives of production and sales of electronic books, we have used statistical and business sources, as well as bibliographic and reference databases. One of the statistical sources we have used is the Panoramica de la edición de libros en España (Overview of book publishing in Spain), which is published every year by the Spanish Ministry of Culture, and which offers all kinds of data regarding the situation of publishing in Spain, with a growing section devoted to the new platforms. The report El Comercio Interior del Libro (Book Domestic Trade) (2009) has been used to know the business context of all the enterprises in our study. This work, published yearly by the Spanish publishers association Federación de Gremios de editores de España, provides varied information about the evolution of the publishing sector in Spain from a business point of view. The Federación de Gremios de editores de España also publishes a study called Hábitos de Compra y Lectura de Libros (Habits of Book Purchase and Reading), which analyzes the evolution of reading habits regarding the new platforms. On the other hand, we have consulted the database Libros Españoles en Venta (Spanish Books on Sale), created with the data of the ISBN offered by the publishers, which currently has 1 million entries of works published in Spain since 1976. This database has been studied in order to contrast all the electronic books that have been published, the publishing houses behind them and the bibliographic control level that exists on them. Likewise, the publishing companies' database, created by the Spanish Ministry of Culture, has been consulted in order to review the publishing prefixes used by the electronic publishers, as well as the collections and titles they have developed. We have also studied all the profiles of the publishing groups of our report, in order to establish a framework for the development and projection of the undertaken initiatives, and in order to propose some reasonable forecasts about their evolution. To do so, we have analyzed all the documents about these companies that were available on their websites, together with scientific articles and sources from newspapers and other media. Finally, we have assessed the experiences that have been developed in the libraries regarding the lending and use of electronic books, by means of a survey that considers these points.

\section{b. Experiences}

In Spain, there are several working experiences with electronic books, mainly through the subscription of collections in university and research libraries. (Alvite Diez; Rodriguez Bravo, 2009). Electronic books have been present for more than a decade, although their distribution and use have been restricted to the academic fields through aggregators such as Ebrary, NetLibrary, Questia, etc. The academic institutions acquired license agreements with which their users could browse the books, although in most occasions several users could not access the same book simultaneously (NetLibrary), and the works could not be reproduced or copied. Likewise, there are some well established digital libraries such as Project Gutenberg or the Biblioteca Virtual Miguel de Cervantes (Miguel de Cervantes Virtual Library), which are crucial portals for accessing classical texts. However, in all cases, the request had to be performed via the computer, which represents an ergonomic and readability hindrance. At this moment, the latest innovation is the development of portable reading devices in which you can download books and other documents, with readability levels that are comparable to those of conventional paper printing. 
However, the latest innovation is represented by the appearance of initiatives for the production and creation of publishing contents in Spain. The publication of electronic books in Spain has gone from being a mid-term possibility, calmly accepted by the publishing sector, to being an unstoppable reality that has forced the main actors in this field to take their positions and to adopt immediate initiatives. In view of the data presented by TodoeBook.com, a web that sells electronic books in Spain, sales increased by $500 \%$ in 2009 , and they will "finally" consolidate in 2010. This phenomenon has gained such a momentum that even the Foundation of Urgent Spanish commented in November 2009 on the proper use in Spanish for the words "libro electrónico", "libro digital" or "ciberlibro" for e-books, and "lector de libros electrónicos", "lector de libros digitales" or "lector de ciberlibros" for reader devices. The Foundation of Urgent Spanish is a non-profit organization with the main objective of promoting a proper use of the Spanish language, especially in the media, and with a growing influence on its development. Oh the other hand, the Spanish Ministry of Culture is preparing a report on this phenomenon, with the assistance of the main actors of the book sector in Spain. The document will bring up some questions, such as the projects and the adaptation of the publishing industry, the use of electronic books in teaching and university research, the changes in the distribution channels and the impact of this new format in the reading habits of the Spaniards. There are other official institutions that have adopted measures that will mobilize the market. To this end, almost 90,000 secondary school students from Catalonia will have access to an electronic purse, recharged by the Education Department of the autonomous government of Catalonia, with which they will be able to purchase digital books in a virtual platform, within the context of the Digital Classroom Program Educa 1x1. The director-general of primary and secondary education of this Department has explained that his government is preparing a platform, together with publishing houses from Catalonia, called Empúries (commerce), in which all the students of this region will be able to purchase digital books with a rechargeable card. According to its forecast, Empúries will serve 90,000 seventh and eighth graders from 70 education centres, and in 4 years it will reach all the students in these stages, before spreading to primary education.

\section{1) Publishing houses}

Several companies have started to work with new formats, anticipating the possible boom of a market that has been almost unexplored by the publishing sector. This phenomenon is scheduled to take place in winter 2009, when portable reading devices will become the topselling Christmas present.

Carmen Balcells was the first professional in the publishing sector to take part in this trend. She is a well-known Spanish literary agent, who was a pioneer in royalty management in Spain. She achieved some very important victories for the authors she represented, such as the elimination of contracts for life or the imposition of clauses for the transfer of a book for a limited time. She founded the literary agency named after her, and she retired in 2000, after being awarded an honorary degree from the Autonomous University of Barcelona, in recognition of her work in the fields of books and culture. She has always been interested in new technologies and innovations in the publishing world, and she has recently signed a 
contract with Leer-e, a company that publishes electronic books, for the marketing of new formats from 100 of her authors. The fact that a literary agent has been the one that adopted this kind of initiatives is somewhat natural within the special nature of the Spanish market. Publishers in the US have control over the electronic rights of their authors, and they can negotiate massive cessions for e-books. In the case of Spain, however, publishers have not the digital rights of their authors, and they must negotiate with each one of them, or with their agents.

The project started by Carmen Balcells is called "Palabras Mayores". It consists of a collection of books by renowned authors from Spain and Spanish America, published as ebooks. That is, they can be read on a computer screen, an electronic reader or even a portable device: a phone or a PDA. We must take into account that Carmen Balcells' agency holds the royalties of the most important authors in the Spanish-speaking world: Cortázar, García Márquez, Cela, Vargas Llosa, etc. The agreement she reached with the online distribution company Leer-e includes the publication on the web of more than 100 titles, so that, by the end of 2009, between 250 and 300 titles can be available online. The importance of this project lies in the fact that it has been developed with a distribution company such as Leer-e, whose main task is the sale of portable reading devices. However, according to the company director, this decision has been taken due to the lack of initiatives by Spanish publishers in the field of e-book marketing. Currently, all these titles can be found in the Mobipocket website, which stores 625 books, and in the online bookstore of the company itself (http://tienda.leere.es/es/catalogo/e-books/palabras-mayores). Works by authors such as Bryce Echenique, Vázquez Montalbán, Julio Cortázar, Juan Goytisolo, Rosa Montero, Miguel Delibes, Miguel Ángel Asturias and Camilo José Cela, among others, can already be found at a price of 5 euros each. All the books are sold in Mobipocket and Epub formats, and they are protected with DRM. The company allows trial downloads for all the books. Currently (November 2009), more than 45 works in this collection have been put for sale. This company is presently marketing more than 600 titles by all kind of authors and subjects, and all of them are available in the abovementioned formats.

However, the ISBN books and publishing houses database have only registered 61 books with an ISBN. This dysfunction not only affects the bibliographic control inherent to all published works, but also their potential visibility. This creates an information problem that must be solved by the publishing companies, especially if we take into account the fact that the Spanish legislation on Copyright deposit does not include Digital Copyright deposits yet. In this respect, the only existing project in Spain is PADICAT (Patrimoni Digital de Catalunya), which has been developed by the National Library of Catalonia. The objective of this project is to collect, process and offer all the popular, cultural and scientific digital production of Catalonia. In sum, the main goal of PADICAT is to file all the web contents of Catalonia. This project was started in June 2005 (http://www.padicat.cat/es/index.php).

The Catalan publishing house Grup 62 and the Institut Cambó have also started a collection of classic titles in e-book format, which represents their first foray into the digital market. Grup 62 is a referent in the Catalan publishing world. It was originally Edicions 62, a 
publishing company founded in 1962 with the objective of creating a modern, general and universal catalogue of the Catalan language, comparable to those of the best European publishing groups. Almost at the same time, in 1964, a Spanish label called Ediciones Península was created. This company has survived until now, and it is currently specialized in non-fiction titles. Since then, the publishing house grew and, in the last decades, it has incorporated other companies or created new labels until it became the current Grup 62. At the end of 2006, after including the Planeta and Enciclopèdia Catalana companies as shareholders, Grup 62 has increased its structure with a very important amount of publishing labels, each one of them with lots of experience. Currently, the labels Proa, Pòrtic and Mina, from the Enciclopèdia group, and Columna and the Catalan collections of Destino, Planeta and Timun Mas, from the Planeta group are part of Grup 62.

The new Grup 62, with a total of 18 publishing labels, covers all the literary genres and all the publication formats. They publish Catalan- and Spanish-language authors, as well as translations from foreign writers.

The collection starts with Tragèdies tebanes, (Theban Tragedies) by Sophocles, and La poesia erotica (The erotic poetry) by Ovid, which are part of the collection Biblioteca de Grecia y Roma (Greece and Rome Library), by the label Bernat Merge, which publishes Greco-Roman classics in Catalan. All books are available in ePub, Mobipocket and PDF formats, and they are marketed through different sales channels, ranging from Grup 62 itself to Casa del Libro, El Corte Inglés or Todoebook, among others. Prices of books in electronic format are similar to those in paper format, and they are relatively high, with $19.50 €$ and $15.60 €$ respectively for Tragèdies tebanes, and $18 €$ and $14.40 €$ respectively for Ovid's poems. This represents a comparative disadvantage for electronic products. Although the proposals for the publication of this kind of works are interesting, they still lack boldness, and they are also hindered by the lack of advertising on the website of the publishing company, which does not include a section for books presented in electronic format. Only well-informed readers will be able to find those titles.

Vicens Vives, together with the Catalan publishing cooperative Abacus, owns $28 \%$ of 36 Lbooks, a company of digital books distribution which also includes the company Cultura 03 and some private investors. Their objective is to normalize the purchases of digital books compared with paper books from the $1^{\text {st }}$ December, in all their 31 stores around Catalonia and the Valencian Community. They have not decided yet which device they will install in their shops for the purchase of electronic books, but they already know which hardware it will be downloaded to: a device called Reader, although they are searching for a more meaningful name in Catalan. This new company wants to become one of the main distributors of digital books both in Spanish and in Catalan for Spain and Spanish America, and also for all the operators in the market: book stores and big shopping centres. They will also have their own virtual shop.

Finally, the companies Santillana, Planeta and Mondadori have also created a publishing platform for the negotiation of the e-book rights of their authors. They do not know yet when 
the paradigm shift will take place, but they think that it will not be a revolution, but an evolution, and they want to be there even if it is not yet an important part of the business. The platform created by these publishers and the literary agents have already reached some agreements, although they have not been signed yet. They want the e-books to be sold in the book stores, through download codes. Alicia González, from the Asociación de Agencias Literarias (Association of Literary Agencies, ADAL), explains: "We will handle the royalties, but we will not ignore the publishers. We are working with them". Their intention is to cede the electronic rights of each title to the company that already has it on paper. Royalties will be higher for e-books (between $25 \%$ and $40 \%$ ) than for paper books (10\%), which have a higher retail price.

Apart from these experiences by big and medium-sized groups, several publishing houses are marketing electronic books through digital platforms of sales and distribution. The most important one in Spain is Todoebook.com (http://www.todoebook.com/index.asp), which belongs to Publidisa, a Spanish company of new technologies for the publishing sector. In Todoebook, any publisher or publishing service from any institution, organization or company can market their books in electronic format via the web. This means that they can reach potential customers from all around the world, and they will also offer their regular customers the possibility of enjoying the advantages of e-books compared with paper books, such as: a lower cost, higher accessibility, immediate availability or better reading tools. Currently it contains a list of more than 25.000 titles that belong to more than 200 publishing groups, most of them from Spain. The books are presented in PDF format with Adobe's DRM. All the books will have a $40 \%$ discount over the paper version, in case there is one.

Luarna (www.luarna.com) is a recently created publishing house that is focused on the publication of digital books that can be displayed in different devices, and specially in the famous eReaders, based on electronic ink technology. Its marked editorial line is based on the publication of varied contents, as long as they are relevant for the cultural, scientific or technical fields, and their authorship can be proven. Luarna's catalogue inludes different genres, ranging from novel, poetry or theatre to essays, research materials on any academic area or publications about technology. Also, thanks to the versatility provided by the Internet, their contents will be developed through different formats, such as books, monographs, articles and multimedia publications.

Finally, the Fundación Germán Sánchez Ruipérez has started a project called Territorio ebook (E-book Territory), which started its pilot stage in summer 2009, and which will be fully implemented in January 2010. Its objective is to analyze the reading process of users, thus being able to anticipate some of the roles that users, librarians, teachers and students will have to adopt in a near future. The research core consists of users of the libraries of the Fundación in Peñaranda and Salamanca: Groups of readers who are more than 55 years old will begin the project, and then, groups of children and young people will progressively join them. All these users, together with groups between 18 and 55 years, will participate in an activity of controlled lending. This will help the researchers know the interaction of these users with the electronic book, as well as their opinion about the reading experience. Among other activities, 
A experiment will be performed with the book El Manuscrito de Piedra, by Luis García Jambrina, published by Alfaguara (the company that has ceded the license for the reproduction of the book in electronic reading devices), in order to contrast the impact of the group dynamics techniques. With this work as a focal point, new contents will be created (dictionaries, short stories, comic books), as well as sound and image files. Also, other contents derived from different dynamic activities such as tourist routes, literary dinners, theatre performances, exhibitions, etc, will be compiled, thus enriching both the individual and social reading experiences.

The goals of this project, which lies on the borderline between the publishing business and the library field are the following:

- To create e-book readers in Peñaranda.

- To research and assess e-book reading habits with a representative sample.

- To design a dynamic project that includes reading promotion, information literacy and Web 2.0.

- To promote an interdisciplinary approach of reading together with other cultural manifestations.

- To assess and spread the experience among the library, publishing, research and cultural fields.

\section{Libraries}

The experience of lending electronic reading devices that has originated in other countries has revealed the existence of a faithful and important group of readers. The most enthusiastic sector with regard to these services is made of young people, "digital natives" used to online reading. Therefore, the industry forecasts a change in the profile of readers as they become more familiar with the new devices and formats. Advantages for users are obvious, because the physical presence of the user will no longer be necessary during the lending process, thus making it easier to access and browse the books.

All the experiences that are taking place in several institutions, both educational and noneducational are divided in two groups:

- Lending the reading device for a limited amount of time with a limited number of titles in it.

- Lending a temporary copy (with a DRM with an expiry date) of the electronic book without any reading device.

The risks of the first method are inherent to the lending of the reading device: they can be damaged or stolen. The second method does not require actually going to the library. The main advantage for librarians is the fact that digital books do not occupy space in the shelves, which is a pressing problem in view of the growing spatial needs of libraries. Also, theoretically, they could be read by several people at the same time, which would solve the existing problem of the high investment required for collections of handbooks that never reach all the students who need them. On the other hand, as it does not wear out, there is no 
need to be constantly replacing the bibliographic material. However, the problem of establishing a model of acquisition has not been solved yet, because e-book prices for libraries would be three times higher than the retail price for a private customer (around $29 €^{2}$ ).

In view of the lowering prices of electronic reading devices, libraries in Spain, which are eager to attract customers that are familiar with digital resources and to capitalize their growing popularity, are starting to loan these devices. Currently, some libraries have implemented this plan, although they are still on trial.

\subsection{Cases}

\section{Library of the University Pompeu i Fabra}

http://www.upf.edu/bibtic/es/recursos/ebooks.html

It includes the lending of e-books and other electronic texts acquired by the Library of the UPF, as well as other free texts that can be accessed online, selected according to their quality and interest. In order to know the available titles, it offers a search engine that classifies them by book and subject. Most of them can be found in PDF format.

\section{Library of the Open University of Catalonia (UOC)}

http://biblioteca.uoc.edu/ebooks/esp/index.html

The UOC loans electronic reading devices for post-graduate students, both in Catalonia and in the rest of Spain, as well as in the reference room of the university. Apart from this new service, the website of the library has opened a section devoted to readers of electronic books. From this site, we can look for all the educational material of the UOC (in PDF, Mobipocket, ePub and HTML formats), as well as the collection of electronic books that are available in the library, open code books and several classic works of the universal literature. This new section also displays the instructions and options of the reading devices. Lending is requested via the catalogue, as if it were a normal book, but the reading device can only be obtained and returned in the support centre. The device can be used for a maximum of 2 hours for references, and this period can be extended if there are no other reservations. The service is currently on trial for 3 months.

Gabriel Ferraté Library (Clavero, et al, 2009)

http://bibliotecnica.upc.es/bib160/traduccio.asp?Idioma=1\&URL=http://bibliotecnica.upc.es/b ib160/serveis/ebooks/inici.asp

This library offers electronic reading devices for its users, so they can experience this kind of reading and access other information. The devices are loaned with memory cards that contain 338 titles. The devices are loaned for a maximum of 10 days, and this period can be extended

\footnotetext{
${ }^{2}$ Rich, M., "Los desafíos en el préstamo de libros digitales". The New York Times, 2009.

http://www.lanacion.com.ar/nota.asp?nota $\mathrm{id}=1187212$ [Accessed on the 9th November 200']
} 
up to 4 times, depending on the availability in the library. Acceptance of the regulations of this service is necessary for home lending.

\section{Complutense University of Madrid}

http://www.ucm.es/BUCM/eis/doc11773.pdf

Lending period will last for 7 days, and it can be extended once for other 7 days. There is a 2day penalty per day of delay. The user will not be able to change or alter the configuration of the reading device. If the user causes any damage due to a misuse of the device, it will be considered as a serious misdemeanour, and it will involve a temporary suspension ranging from 1 to 3 months. The users will also be responsible for the cost repair of any damages caused to the device. The users will sign a document in which they state their agree with the terms of the normative.

\section{Library of the Faculty of Computing of the Complutense University of Madrid}

http://www.ucm.es/BUCM/eis

This library has a specific normative for the lending of electronic books (http://www.ucm.es/BUCM/eis/doc11773.pdf). It offers 6 reading devices for book lending: 3 Sony PRS-700, 1 Iliad and 2 Hanlin V3. The lending period lasts one week, and it can be renewed for another week. For Sony models, memory cards are provided. Books are in Mobipocket, ePub and PDF format. The collection of electronic books that can be borrowed can be checked at http://www.ucm.es/BUCM/eis/29731.php.

\section{Conclusions}

The publication of electronic books is still an incipient sector in Spain, and its future is not without uncertainties. We cannot forget that the success of a book, regardless of the format, depends on a specific alchemy that can never be completely controlled. Publishing is a sector in which the feeble growth of final markets can be compensated for by an improvement of the margins of benefits caused by a successful rationalization and a constant reassessment of the company assets, assisted by the bids of potential newcomers. The publication of electronic books all over the world has shown higher permeability to the arrival of new actors than conventional publishing. An idea, an author, a concept, a collection, together with the necessary will to impose and defend a certain product can still create a success that stimulates the ambitions of newcomers. These weak barriers contribute to the creation of a constant trend of re-classification, as the market exerts its power, choosing some works and ignoring others. Meanwhile, those groups who want to expand their niche and distribute the costs of their marketing, distribution and diffusion channels over a growing number of titles promote the growth of new trends (in this case via the migration to other formats), as can be seen with all the initiatives that the main publishing groups in Spain have initiated.

The objective of these groups is to develop a protection strategy before the general public, occupying market sectors that are potentially successful, as in the case of electronic books. To 
do so, they control the access to a wide distribution network, which is an essential condition for a proper marketing of the products, as well as the implementation of an economy of scale wherever possible, so that they can take advantage of their corporative investments, mainly with regard to their brand image. All the big publishing houses apply the logic of vertical integration, aimed to the preservation of the control of added value in the creation of new contents. To this strategy, they are adding horizontal integration, which increases the value of any symbolic content that is presented as text, sound and image, and which can be marketed digitally. Once that the companies have achieved a certain level of experience, the main challenge they face is to become electronic publishers, capable of controlling all the potential alterations in their products, from written format to images. Such a control will create fruitful exchanges among the different elements of the companies. The publishing groups must perform an in-depth analysis of their assets, so that they can make good use of them in a new direction. This will improve the value of their files and their potential change towards other platforms and formats.

The development of Internet and the globalization of communications have designed a new scenario in which the framework for the development of the publishing sector will not be the national foundation of the publishing groups, but the linguistic platforms that can spread around the entire world.

In accordance with this trend, libraries have started to develop projects with the new formats, creating lending systems that help the users become familiar with them. Libraries were already working in a digital context since electronic journals displaced paper journals in the production and reception of scientific contents. Now starts the age of electronic books.

In Spain, this trend has gained lots of momentum in the year 2009, and there are forecasts of a greater growth in the following years, due to the involvement of important publishing groups in the initiatives of production and reception of electronic books.

The electronic book is becoming an unavoidable reality that must be faced by all publishers sooner or later, given the success and popularity of the new reading devices. According to the consulting firm ISuppli, five million devices were sold in 2009, and 12 millions will be sold in 2010. These devices still present obvious limitations, such as the predominance of black and white, the lack of multimedia applications, such as video reproduction, or the waiting time for page turning. However, these drawbacks can be overcome with time. In 2010 we will see color devices with touchscreen, increased wi-fi connectivity or 3G technology in the new readers, and there will be an increase in their features, in accordance with a mature market used to these devices, not unwilling to changes. The increase in the offer of titles and the publishing developments will also favour this progressive adaptation. Publishing in general, and academic and university publishing in particular must adapt to these changes, because these new formats increase the velocity, topicality and visibility of scientific research, and they are fully integrated in the philosophy of the European Higher Education Area. Moreover, electronic books are more eco-friendly, they save space and maintenance time, and they offer several features for different types of disabilities (both hearing and visual). Therefore, they 
have become an optimal tool for the practices of reading and lending in libraries. The history of culture and documentation shows that the appearance of new media implies a redistribution of roles for the previous ones, and that this is not a matter of replacements, but of convergences and complementarities. In the case of electronic books, their presence in our life is already an indisputable fact, and the different links of the publishing chain will have to adapt to it, lest they are left out of the game. This might be the case of bookstores, which already have an immediate precedent in video rental stores and record shops. Publishers need to start thinking about the inevitable digital future that awaits, but authors and readers will have to as well.

\section{REFERENCES}

Alvite Diez, Luisa; Rodriguez Bravo, Blanca (2009). E-books in Spanish libraries. The Electronic Library, vol. 27, n. 1, pp. 86-95.

AMERICAN PUBLISHERS ASSOCIATION (AAP) (2009). Industry statistics.

(http://www.publishers.org/main/IndustryStats/indStats 02.htm)

Anderson, B. E-book growth. Behavioral and Social Sciences Librarian, 28, pp. 74-76.

Bellaver, R.F.; Gillette. (2004). The usability of e-book techology: practical issues of an application of electronic textbooks in a learning environment. http://publish.bsu.edu/cics/e-book final result.asp

Berube, L. (2005). E-books in public libraries: a terminal or termination technology?. Interlending and Document Supply, 33, 1, pp. 14-18.

Centre for Information Behaviour and the Evaluation of Research (CIBER), (2008) Information Behaviour of the Researcher of the Future. http://www.ucl.ac.uk/ciber/ciber.php

Clavero, J., Codina, L., Miquel , Pérez, A., AND Serrat-Brustenga, M., "Estudio de caso de servicio de préstamo de libros electrónicos". Profesional de la información, El, Vol. 18, N. 2, 2009, pp. 237-242. http://upcommons.upc.edu/e-prints/bitstream/2117/2846/1/clavero_estudiocaso.pdf

Comercio Interior del Libro (2009). Madrid, Federación de Gremios de Editores.

Dillon, A., Gabbard, R. (1998) Hypermedia as and educational technology: a review of the quantitative research literature learned comprehension, control and style. Review Educational Research, 68, 3, pp. 322-349.

Doctorow, C. (2004). Neither E, nor books. En: papers for the O'Really emerging technologies conference. San Diego.

Dosdoce (2009). Digitalización del libro y uso de las redes sociales en el sector editorial. http://www.dosdoce.com/continguts/estudios/vistaSola_cas.php?ID=24

Federación de Gremios de Editores; Fundación Germán Sánchez Ruipérez (2010). Encuesta sobre el libro digital: impacto de la digitalización en el catálogo, canales de distribución y de venta y política de precios. Madrid, Federación de Gremios de Editores, Fundación Germán Sánchez Ruipérez. 
International Digital Publishing Forum (IDPF) (2006). E-book Survey 2006.

International Digital Publishing Forum (IDPF) (2009). Digital Book 2009. International Digital Publishing Forum

Joint Information Systems Committee (JISC), (2008). JISC National E-Books Observatory Project, Results of First User Survey. http://www.jisc.ac.uk/

Just, P. (2007). Electronics books in the USA: their numbers and development and a comparison with Germany. Library Hi Tech, vol. 25, n. 1, pp. 157-164.

Landoni, M; Hanlon, G. (2006). E-books reading groups: interacting with e-books in public libraries. The Electronic Library, 25, 5, pp. 569-612.

Mclellan, R.J.; Hawkins, N. (2006) Perspectives on the use and development of a broad range of ebooks in higher education and their use in supporting virtual learning environments. The Electronic Library, v. 24, n. 1, pp. 68-82

Nelson, M. (2008). E-books in higher education: nearing the end of the era or Hype?. Educase review, 43, 2, pp. 40-56.

Outsell, Inc.(2009). E-books Market size, Share and forecast 2009.

Panorámica de la edición española de libros (2009). Madrid, Ministerio de Cultura.

Publishers Communication Group, (2008). E-Books in 2008: Are Librarians and Publishers on the Same Page? http://www.pcgplus.com/Newsletter/Issue10/E-Book_Survey_Results.pdf

Rao, S.S. (2005). Electronic books: their integration into library and information center. The Electronic Library, vol. 23, n. 1, pp. 116-140.

Secker, J; Plewes, L (2002). Traditional and electronic study pack: a case study of the production process. Program, vol. 36, no 2, pp. 99-108.

http://www.emeraldinsight.com/Insight/ViewContentServlet?Filename=Published/EmeraldFullTextAr ticle/Articles/2800360203.html

Springer, (2007). E-books - Costs and Benefits to Academic and Research Libraries. http://www.springer.com/?SGWID=6-102-0-0-0

Stelle, L. Woodward, H, (2009). Understanding how student and faculty really use e-books. Joint Information Systems Committee (JISC). http://www.jisce-booksproyect.org. 


\section{Full name: José Antonio CORDÓN GARCÍA}

Affiliation: Professor of Bibliography and Electronic Publishing of the Faculty of Translation and Library and Information Science at the University of Salamanca

E-mail address: jcordon@usal.es

Full international contact details: Universidad de Salamanca. Facultad de Traducción y Documentación C/Francisco Vitoria 6-16 37008 Salamanca. (Spain). Teléphone number: +34-923 294580 Fax: +34-923 294582

Brief professional biography:

José Antonio Cordón has a PhD in Documentation and a degree in History from the University of Granada. His educational work lies in the areas of publishing research and information sources. Among his publications are 'Quality assessment of Spanish universities' web sites focused on the European Research Area', Scientometrics (2005) and 'The Citizens' Europe: The challenges of gaining access to and preserving culture', Fundacion Academia Europea de Yuste, (2007) and other articles. He has performed and taught a lot of courses and has written a wide variety of items, related to information sources, scholarly publishing, digital books and reference managers. He directs the Masters in Publishing at the University of Salamanca.

\section{Full name: Julio ALONSO ARÉVALO}

Affiliation: Chief Librarian of the Faculty of Translation and Library and Information Science at the University of Salamanca

E-mail address: alar@usal.es

Full international contact details: Universidad de Salamanca. Facultad de Traducción y Documentación C/Francisco Vitoria 6-16 37008 Salamanca. (Spain). Teléphone number: +34-923 294580 Fax: +34-923 294582

Brief professional biography:

She currently works as Chief Librarian of the Faculty of Translation and Library and Information Science at the University of Salamanca since 1992. He has developed several projects: Digitalia: Informational resources portal of Library and Information Science; Manage and moderator of the mailing lists with more impact in the professional field in Spanish: INFODOC http://listas.bcl.jcyl.es/infodoc/; $\mathrm{He}$ is editor of the open access repository E-LIS http://eprints.rclis.org/; It is part of the scientific committee of the journals Ciencias de la Información y Acimed (Cuba). He has performed and taught a lot of courses and has written a wide variety of items, related to open access issues, digital books and reference managers. It has published the annual report Informe APEI sobre Acceso Abierto. In closing comment that directs the Universo Abierto Blog

\section{(c) Emerald Group Publishing Limited}

This is a pre-print of a paper and is subject to change before publication. This pre-print is made available with the understanding that it will not be reproduced or stored in a retrieval system without the permission of Emerald Group Publishing Limited. 


\section{Full name: Helena MARTíN RODERO}

Affiliation: Chief Librarian of the Faculty of Medicine at the University of Salamanca

E-mail address: helena@usal.es

Full international contact details: Universidad de Salamanca. Facultad de Medicina. Campus Miguel de Unamunos 37007 Salamanca. (Spain). Teléphone number: +34-923 2945 oo - Ext. 1846 Fax: +34-923 294519

Brief professional biography:

She has degrees in Roman Philology (specialty in French studies) and Arabic Philology at the University of Salamanca. She has been librarian in the University of Santiago de Compostela and University of Vigo (Spain). She currently works as Chief Librarian of the Faculty of Medicine at the University of Salamanca (Spain)She has published in different specialized journals and has participated in several post-graduate programs and courses as well as in technical innovation projects funded by the Ministry of Education and Science and the Fundación Española para la Ciencia y la Tecnología (FECYT). She manages and moderates the mailing list INFODent and directs the USALbiomédica blog ( http://www.usalbiomedica.com) 